\title{
O Binônimo: Inflação-Desenvolvimento
}

\author{
Chagas Melo
}

\begin{abstract}
A
emissão de papel-moeda para cobrir deficits orçamentários ou financiar produtos não exportados tem sido uma das caracteristicas fundamentais da inflação brasileira.
\end{abstract}

Quando o papel-moeda de curso forçado é destinado a investimentos de imediata produtividade, os seus efeitos inflacionários são logo atenuados. Entretanto, dado o caráter dos investimentos exigidos nos países subdesenvolvidos, isto é, estradas ou indústrias pioneiras e outros empreendimentos de produtividade remota, o financiamento dêsses empreendimentos com emissões pode desencadear violentas pressões inflacionárias.

O Professor Richard Lewinsohn em "Causas e Remédios da Inflação" - Revista do Serviço Público de janeiro de 1944, pág. 28, salienta o seguinte: "Qualquer que seja a causa da inflação, seu efeito é sempre o mesmo: a população deve pagar uma despesa, que não é financiada de outra maneira, pela aceitação de uma moeda inflada e, por isso mesmo depreciada. A inflação é, portanto, uma forma de tributação indireta, pagável no momento em que a moeda é trocada em mercadorias ou serviços. E' um encargo difuso, sem tarifa nem limites, proporcional à quantidade de moeda retida pelo indivíduo, mas progressivo no tempo; um impôsto particularmente injusto, porque atinge as diversas categorias da população de maneira muito desigual e arbitrária, e também, com o tempo, um impôsto antieconômico, porque, depois de haver animado durante algum tempo a marcha dos negócios, entrava a produtividade pelas perturbações sociais que provoca".

Parte do financiamento do desenvolvimento industrial do Brasil tem sido pago através de emissões de papel-moeda. 
O meio circulante cresceu desordenadamente, conforme se vê do quadro abaixo:

MEIO CIRCULANTE

VALORES EM FIM DE ANO

\begin{tabular}{|c|c|c|c|}
\hline & ANOS & $\mathrm{Cr} \$ 1.000 .000$ & Indices $(1951-100)$ \\
\hline 1951 & & 35.319 & 100 \\
\hline 1952 & & 39.282 & 111 \\
\hline 1953 & & 47.004 & 133 \\
\hline 1954 & & 59.041 & 167 \\
\hline 1955 & & 69.340 & 196 \\
\hline 1956 & & 80.819 & 229 \\
\hline 1957 & & 96.575 & 273 \\
\hline 1958 & & 119.814 & 339 \\
\hline 1959 & & 154.600 & 438 \\
\hline 1960 & & 206.100 & 584 \\
\hline 1961 & & 313.900 & 889 \\
\hline 1962 & & 480.000 & 980 \\
\hline
\end{tabular}

A emissão de papel-moeda para fins de investimentos sòmente em casos especiais deve ser usada, a fim de evitar o desencadeamento de pressões inflacionárias.

O Professor Richard Lewinsohn em "Causas e Remédios da Inflação" - Revista do Serviço Público, janeiro de 1944 , pág. 30 diz: "que a tarefa principal de tôda ação antiinflacionista é sempre interromper a emissão de papel-moeda. Não há, entre os economistas, divergências sôbre o ponto de que a emissão de papel-moeda para fins orçamentários deve ser totalmente suprimida. Para atingir êsse objetivo, nenhum sacrifício de ordem f́iscal é por demais pesado, porque a inflação representa para a economia nacional em seu conjunto o pior de todos os impostos".

O processo inflacionário que se desenvolve no Brasil tem origens remotas, reportando-nos porém ao início da Segunda Guerra Mundial, quando o Govêrno teve de emitir para pagar 
os exportadores brasileiros, cujas divisas ficaram congeladas no exterior, em virtude das dificuldades das trocas internacionais, pela paralisação quase completa do comércio exterior.

Não há dúvida, porém, de que êsse processo inflacionário se acelerou com a politica desenvolvimentista posta em prática pelo Govêrno, refletindo-se em um aumento dos preços e restrição do crédito para as médias e pequenas emprêsas.

RAúl Prebisch distingue dois tipos de inflação: a de custos e a de investimentos. A primeira destina-se a cobrir um aumento de custo; a segunda visa a cobrir uma intensificação de investimentos. A inflação de investimentos inicia-se com uma concessão de créditos por parte do sistema bancário, o que ocasiona, inicialmente, uma elevação de preços e, em seguida, de custos. Na inflação de custos, pelo contrário, o sistema bancário é colocado diante do fato de um aumento inicial de salários obtido por entidades de classe apoiadas pelo Govêrno.

Ora, PrEBISCH sustenta que a inflação de investimentos pode ter um papel importante no aumento da poupança. Isso porque ela provoca uma redistribuição da renda em favor das classes abastadas que consomem, via de regra, menor proporção de seus rendimentos.

Conclui, pois, nosso autor que a "inflação em condições ideais poderia dar impulso considerável ao desenvolvimento econômico de qualquer pais. Ela é importante, sobretudo, quando não se pode obter capitais estrangeiros" Apud Joño Paulo de AlmeIda Magalhães "Condições Econômicas do Desenvolvimento - Separata da Revista Estudos Econômicos n ${ }^{\mathrm{s}} 14-15$ de 1954, página $115^{\prime \prime}$.

O problema do financiamento do nosso desenvolvimento econômico é assunto muito complexo. Os capitais estrangeiros não afluem regularmente, exigindo, ainda, vantagens especiais. O remédio é mesmo promover o nosso desenvolvimento econômico por meio de um custeio misto de poupança, capitais externos, sejam públicos ou privados, e mesmo provocando certas pressões inflacionários que, no entretanto. devem ser controladas.

Êsse contrôle deve partir do pressuposto de que a política desenvolvimentista não deve ser unilateral, no setor das indústrias. Um aumento da produção agrícola, bem como dos meios de distribuíla por todo o território nacional, é básico para que seja evitada a espiral dos preços dos produtos agricolas, uma das manifestações do processo inflacionário. Assim, os investimentos iniciais, ou parte dêles, deve orientar-se nesse sentido e não em obras de produtividade remota como aconteceu no qüinqüênio que se findou em janeiro de 1961 . 
De nossas modestas observações, podemos concluir, como já fizeram ilustres economistas, que desenvolvimento econômico sem ajuda externa ou sem inflação é difícil, principalmente nos países onde a capacidade de poupança e de acumulação de capitais é bastante reduzida.

O Professor JAY W. Wiley em conferência pronunciada no Conselho de Economia, Revista do Conselho de Economia, julho. agôsto de 1957, observa o seguinte: "Se um programa oficial de desenvolvimento econômico deve ser executado sem inflação, torna-se necessário que o respectivo financiamento seja obtido por meios não inflacionários ou que haja uma redução dos gastos governamentais em outros setores. Êsse problema abrange todos os órgãos governamentais do pais, órgãos federais, autarquias, órgãos dos governos estaduais e municipais. Enquanto houver autonomia em relação ao dispêndio entre os diversos órgãos governamentais, provàvelmente haverá superlocação. Deveria haver uma subordinação de todos os orçamentos federais a um órgão geral de contrôle, um bureau do orçamento, que verificasse o mérito de cada tipo de despesa. Os governos estaduais e locais devem recorrer a fontes não inflacionárias para atender aos seus gastos. Além disso, deve ser estabelecido um programa ordenado de gastos a ser executado segundo a capacidade do país. Deve ser assinalado que a procura de fundos no setor privado compete com a do setor público e a expansão do investimento privado não deve ser contrabalançada por uma redução no dispêndio público, se se pretende que o "gap" inflacionário seja reduzido".

O esquema proposto acima pelo ilustre Prof. Wiley pode perfeitamente ser aplicado no Brasil, onde a inflação assume aspectos multiformes, como sejam inflação de custos resultante dos constantes aumentos de salários, desorganizando o mercado de crédito, estrangulando as pequenas e médias emprêsas, e uma inflação monetária onde, apesar das constantes emissões, o capital torna-se difícil, concentrado em mãos de pequenos grupos que são os beneficiários da inflação.

O binômio inflação desenvolvimento pode ser aplicado no Brasil, desde que haja uma seleção de investimentos em setores como o de energia elétrica, petróleo, sideźrúrgica, e não no custeio de serviços deficitários como os da marinha mercante e ferrovias, ou de obras suntuárias, como as da nova Capital da República.

Financiar investimentos através de processos inflacionários, principalmente investimentos improdutivos como aconteceu no qüinqüênio 1955 1960, só agravou as nossas dificuldades econômicas, e os benefícios de politica desenvolvimentista não foram compensadores em face dos gastos efetuados exatamente pelas falhas do seu financiamento. 
Salientando o aspecto negativo da inflação, disse o Conselho de Ministros no Programa de Govêrno (D. C. de 29-9-1961):

"O nível geral de preços no Brasil, partindo de uma base de 100 no ano de 1947, atingiu em 1960 o índice de 739 . Essa aguda inflação teve as conseqüências previsíveis: desestimulou a poupança individual, prejudicou os grandes investimentos a longo prazo, desequilibrou o balanço de pagamentos, desviou recursos para ocupações estéreis; e - mais grave que tudo isso - provocou tensões sociais, pois que, ao lado do enriquecimento de um pequeno número de indivíduos, provocou penosas dificuldades para a grande massa do povo brasileiro, sobretudo a população modesta, que viu seus proventos e salários diàriamente corroídos pela alta dos preços. Reproduzindo a experiência de outros paises, não se comprova nenhuma correlação positiva entre inflação e crescimento, pois que tanto o nivel de investimento quanto o ritmo de crescimento variavam muito em função da melhoria das relações de troca ou do afluxo de recursos externos que do ritmo inflacionário, não parecendo que o mecanismo de poupança forçada se tenha traduzido em incremento real do nivel de investimento".

Concluindo suas considerações diz o Conselho de Ministros:

"Não reconheço como válida qualquer tese que pretenda opor a estabilidade monetária ao desenvolvimento. Ao contrário: a estabilidade é o melhor clima para o desenvolvimento, e a nossa inflação não é um preço dêsse desenvolvimento, mas é em parte o resultado de tentarmos financiar investimento por métodos inflacionários. De nos preocuparmos mais com o investimento do que com a poupança que o condiciona. De agravarmos as pressões inflacionárias decorrentes dos investimentos, alongando o prazo de sua maturação pela incapacidade de optar, atacando simultâneamente um número exagerado de empreendimentos. Do planejamento insuficiente, que permite a formação de pontos de estrangulamento e de capacidade ociosos. E, principalmente, dos desperdícios nos investimentos públicos. Mas não é bastante nos limitarmos a reconhecer a compatibilidade entre os dois objetivos, ou procuramos corrigir a inflação sem prejudicar o ritmo de desenvolvimento. Não obstante a importância e a premência do problema da inflação, jamais devemos perder de vista que o maior objetivo nacional - que constitui projeto sem alternativa para a nossa geração - é o desenvolvimento econômico e social. 
Porque a longo prazo só existe um perigo ou um impasse para a nação crescer em ritmo insuficiente para absorver produtivamente o aumento da sua população, oul não conseguir atingir o ritmo de incremento da renda per capita suficientemente rápido para assegurar perspectivas de condições de vida mais humanas, a tôda a população brasileira". 